\title{
Dois casos de ATSM analisados através de balanço de calor parcial para o Atlântico Sudoeste
}

\author{
Isabel P. Silveira ${ }^{1}$, Luciano P. Pezzi ${ }^{1}$, Ronald B. Souza ${ }^{2}$ \\ ${ }^{1}$ Centro de Previsão de Tempo e Estudos Climáticos, Instituto Nacional de \\ Pesquisas Espaciais (CPTEC/INPE) \\ ${ }^{2}$ Centro Regional Sul de Pesquisas Espaciais, Instituto Nacional de Pesquisas \\ Espaciais (CRS/INPE), Santa Maria, RS \\ e-mail:isabel.silveira@cptec.inpe.br
}

\section{Introdução}

Anomalias de temperatura da superfície do mar (ATSM) vem sendo observadas no Atlântico Sudoeste e discutidas ao longo das reuniões climáticas mensais do CPTEC/INPE. A compreensão e a boa representação desses campos podem indicar previsões mais realísticas de tempo e clima, uma vez que se usa a persistência de ATSM para gerar análises.

O balanço de calor (BC) nas camadas superficiais do oceano pode sugerir explicações atmosféricas e oceânicas sobre o aparecimento dessas anomalias (Dong e Kelly, 2004). Logo, o objetivo desse trabalho é determinar através do $\mathrm{BC}$ os principais agentes contribuintes para o surgimento de ATSM nessa região do planeta.

\section{Materiais e métodos}

O balanço de calor parcial e superficial do oceano (BC) foi determinado para as saídas do Modular Ocean Model (MOM-4), para os anos de 1964 e 1992, de ATSM negativa e positiva, respectivamente, a partir da Eq. Tridimensional da temperatura do mar (Menkes et al., 2006).

$\partial_{t} T=-u \partial_{x} T-v \partial_{y} T-w \partial_{z} T+D_{l}(T)+D_{z}(T)+l(Z)$

Onde T é a temperatura potencial, $(\mathrm{u}, \mathrm{v}, \mathrm{w})$ são as componentes de corrente oceânica, $D_{l}(T)$ é o operador de difusão lateral, $D_{z}(T)$ é o operador de difusão vertical, $l(Z)=Q_{s} \partial_{Z} f_{(Z)}$ é a quantidade de calor du- 
rante a penetração do fluxo de calor solar, $Q_{s}$ é a radiação incidente, $f(z)$ é a fração de radiação solar que alcança a profundidade $z$.

\section{Resultados e discussões}

As principais componentes do BC para o Atlântico Sudoeste são a contribuição climatológica e anômala da coluna de água, a contribuição atmosférica e a advecção climatológica de calor. A advecção anômala de calor, assim como a difusão lateral teve valores inexpressivos para a média anual. Esses dois termos adquirem maior importância em meses específicos, onde ocorrem eventos de mesoescala, como o desprendimento de vórtices da Corrente do Brasil, a difusão passa a ser um fator importante. A contribuição da coluna de água para ambos os anos, negativo e positivo, equivale a mais de $50 \%$ do balanço de calor para a região da CBM. A contribuição atmosférica é equivalente em magnitude à contribuição climatológica da coluna de água em ambos os casos, sugerindo interação entre os primeiros 200 metros de coluna de água e a atmosfera sobrejacente.

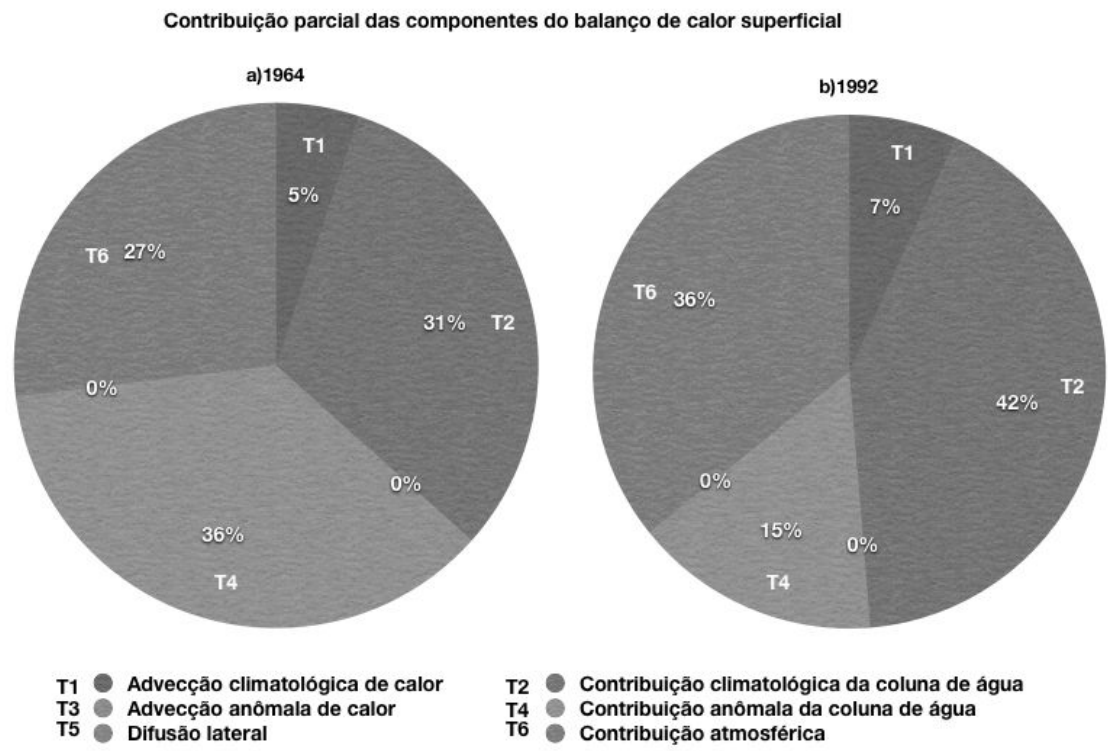

Figura 1. Contribuição parcial das componentes do balanço de calor superficial para os anos de a) 1964 (anomalia fria) e b)1992 (anomalia quente). 
A contribuição da coluna de água está relacionada ao forte gradiente térmico entre a superfície e a camada de 200 metros de profundidade. Anomalias no contraste térmico das frentes oceânicas podem ser relacionadas às variações nos transportes das correntes de contorno assim como, no transporte e na altura da camada de Ekman no oceano. As anomalias frias de 1964 podem ser explicadas pelo enfraquecimento da contribuição atmosférica e pelo aporte de água anomalamente fria na coluna de água. Por outro lado, o ano de 1992, onde foram registradas ATSM positivas, apresentou aumentos nas contribuições da atmosférica e no gradiente térmico da coluna de água, assim como na advecção climatológica.

\section{Conclusões}

Conclui-se dessa forma, que o BC da região da CBM para os anos anômalos de 1964 e 1992 está vinculado às alterações na coluna de água, possivelmente interligadas às mudanças na circulação atmosférica de meso e de largas escalas. Essas podem afetar o transporte de Ekman, assim como alterar as taxas de obducção ou a subducção local.

\section{Referências}

DESER, C., ALEXANDER, M. A. e TIMLIN, M. S. Understanding the persistence of sea surface temperature anomalies in midlatitudes. J. Climate 16: p. 52-72, 2003.

MENKES, C. E. R., VIALARD, J. G., KENNAN, S. C., BOULANGER, J.-P. e MADEC, G. V. A modeling study of the impact of tropical instability waves on the heat budget on the Eastern equatorial Pacific. American Meteorological Society, p. 847-865, 2006. 